\title{
The safety of combining angiotensin-converting-enzyme inhibitors with angiotensin-receptor blockers in elderly patients: a population-based longitudinal analysis
}

\author{
Finlay A. McAlister MD MSc, Jianguo Zhang MSc, Marcello Tonelli MD SM, Scott Klarenbach MD MSc, \\ Braden J. Manns MD MSc, Brenda R. Hemmelgarn MD PhD; on behalf of the Alberta Kidney Disease Network
}

See related commentary by Phillips at www.cmaj.ca/cgi/doi/10.1503/cmaj.110366.

\section{- Abstract}

Background: The risks associated with using an angiotensin-converting-enzyme (ACE) inhibitor and an angiotensin-receptor blocker together are unclear. This study was designed to determine the safety of combination therapy with these two drugs in clinical practice.

Methods: We conducted a population-based longitudinal analysis using linked administrative and laboratory data for elderly patients who were new users of an ACE inhibitor, an angiotensin-receptor blocker or a combination of both medications between May 1, 2002, and Dec. 31, 2006. We compared outcomes in patients given combination therapy versus patients given monotherapy using Cox proportional hazards analyses with adjustment for baseline characteristics.

Results: Of the 32312 new users of either medication (mean age 76.1 years, median creatinine level $92 \mu \mathrm{mol} / \mathrm{L}), 1750(5.4 \%)$ received combination therapy. However, 1512 (86.4\%) of the patients who were given combination therapy did not have trial-established indica- tions such as heart failure or proteinuria. Renal dysfunction was more common among patients given combination therapy (5.2 [95\% confidence interval (Cl) 3.4 to 7.9] events per 1000 patients per month) than among patients given monotherapy $(2.4[95 \% \mathrm{Cl} 2.2$ to 2.7] events per 1000 patients per month) (adjusted hazard ratio [HR] 2.36, 95\% Cl 1.51 to 3.71). Hyperkalemia was also more common among patients given combination therapy (2.5 [95\% Cl 1.4 to 4.3] events per 1000 patients per month) than among patients given monotherapy $(0.9$ [95\% Cl 0.8 to 1.0$]$ events per 1000 patients per month) (adjusted HR $2.42,95 \% \mathrm{Cl} 1.36$ to 4.32 ). Most patients took combination therapy for only a short time (median three months before at least one agent was stopped).

Interpretation: Combination therapy was frequently prescribed for patients without established indications and was associated with an increased risk of adverse renal outcomes when compared with monotherapy. These results mirrored data from randomized controlled trials.
$\mathrm{R}$ enin-angiotensin system combination therapy with concurrent use of angiotensin-converting-enzyme (ACE) in hibitors and angiotensin-receptor blockers confers additional benefits over the use of either agent alone for certain patients who have diabetic nephropathy or advanced systolic dysfunction of the left ventricle..$^{1-3}$ However, randomized controlled trials (RCTs) have reported an in creased risk of renal dysfunction among patients given combination therapy compared with patients given an ACE inhibitor or an angiotensinreceptor blocker alone (i.e., monotherapy). ${ }^{4.8}$

It is not known whether the absolute risks of adverse renal outcomes would be the same in clinical practice as they are in RCTs. ${ }^{6-8}$ It is often assumed that RCTs underestimate the absolute risks of adverse events because trial participants are generally younger, healthier and more highly selected than patients in clincal practice; trials with run-in periods exclude patients with early adverse events; and trials are often too short or samples too small to detect infrequent adverse events. ${ }^{9}$ On the other hand, RCTs may overestimate risks relative to clinical practice for several reasons: higher doses of the drugs are used; laboratory testing is more frequent, so asymptomatic laboratory perturbations are more likely to be detected; and systematic reviews of trials often exclude trials that do not report any adverse events. ${ }^{78}$ Some have speculated that the renal toxicity of combination therapy with ACE inhibitors
Competing interests:

Braden Manns has received grants from Amgen and Merck. No other competing interests were declared.

This article has been peer reviewed.

Correspondence to: Dr. Finlay McAlister, finlay.mcalister@ualberta.ca

CMAJ 2011. DOI:10.1503 /cmaj.101333 
and angiotensin-receptor blockers that has been reported in clinical trials would not be seen in clinical practice because clinicians could individualize the dosing of both drugs and thereby minimize the risk. ${ }^{10}$

We designed this study to determine the risks of renal dysfunction and hyperkalemia for patients who had recently started treatment with an ACE inhibitor, an angiotensin-receptor blocker or a combination of the two in clinical practice. We also wanted to see whether these risks and the rates of stopping therapy were higher among users of combination therapy than among users of monotherapy. In addition, we looked at the clinical features of patients who were given a prescription for an ACE inhibitor, an angiotensin-receptor blocker or a combination of the two to determine whether combination therapy was being given to patients for whom it had proven beneficial in trials.

\section{Methods}

\section{Study cohort}

We conducted a retrospective cohort study that used a central repository of laboratory data and administrative data for all individuals living in the province of Alberta, Canada. ${ }^{11}$ The four administrative databases were linked to the laboratory data using each patient's unique Alberta Health Care number. All four databases include data on demographics, hospital admissions, emergency department visits and physician claims for all 3.5 million residents of Alberta and have been shown to be highly accurate. ${ }^{12}$ Electronic safeguards (e.g., scrambling of personal health numbers) were used to protect the anonymity of each patient. For patients over the age of 65 years, information on their use of prescription medications was also linked.

The cohort included all residents of Alberta aged 66 years and older who had at least one record within the central laboratory repository and who were new users of an ACE inhibitor, an angiotensin-receptor blocker or both between May 1, 2002, and Dec. 31, 2006. New users were considered to be patients who had received at least two prescriptions for either agent (identified as continuous users) and who had not used an ACE inhibitor or angiotensin-receptor blocker in the 150 days before their first laboratory measurement. We excluded patients who were re ceiving dialysis or who had received a kidney transplant before their initial prescription for an ACE inhibitor or angiotensin-receptor blocker, as well as patients who did not have their serum creatinine level measured after they started taking the medications.

\section{Definitions of exposures}

Patients were placed in the monotherapy group if they met one of two criteria: they used either an ACE inhibitor or an angiotensin-receptor blocker alone throughout the study, or they switched from one type of medication to the other during the study (i.e., patients had used both an ACE inhibitor and an angiotensin-receptor blocker, but the medications had not been coadministered within 120 days of each other).

Patients were placed in the combination therapy group if they had received prescriptions for both an ACE inhibitor and an angiotensinreceptor blocker within 120 days of each other, with subsequent refills for both drugs. As per current recommendations and previous studies, ${ }^{13,14}$ we chose a 120-day interval to define stoppage of medication or concomitant use of drugs, because the median duration of a prescription for an ACE inhibitor or an angiotensin-receptor blocker in Alberta is 61 days.

Although we used new prescriptions to identify patients for our cohort, we examined renewal prescriptions to determine whether patients shifted between groups after entry into the cohort. For example, if a patient prescribed monotherapy was subsequently given a prescription for combination therapy more than 120 days later, the period they used the monotherapy was included in the analyses for the monotherapy group and the period they used the combination therapy was included in the analyses for the combination therapy group.

We extracted data on comorbidities using case-definition algorithms previously validated for administrative data from Alberta. ${ }^{12,15} \mathrm{We}$ defined baseline use of medications as use of drugs prescribed concomitant with, or in the 120 days before, the index prescription of an ACE inhibitor or an angiotensin-receptor blocker.

\section{Follow-up}

For monotherapy users, follow-up began on the date of their initial prescription for either study drug and continued until monotherapy ended (i.e., use of the medication ended or combination therapy began), dialysis began, the patient died, the patient left the province or Mar. 31, 2007.

For combination therapy users, follow-up began on the date they filled a prescription that resulted in concurrent use of both study drugs and continued until either or both of the medications were stopped, dialysis started, the patient died, the patient left the province or Mar. 31, 2007.

\section{Outcome measures}

The primary outcome was the ONTARGET renal outcome of "doubling of serum creatinine or development of end-stage renal disease re- 
quiring dialysis or all-cause death" ${ }^{6}$ within six months among new users of combination therapy versus monotherapy. We also examined the incidence of hyperkalemia (serum potassium $\geq 6.0 \mathrm{mmol} / \mathrm{L}$ ) and stopping treatment within six months of the initial prescription among patients given combination therapy versus patients given monotherapy.

\section{Statistical analysis}

We compared the baseline characteristics of users of combination therapy (at the time they met the definition for combination therapy) with those of the users of monotherapy using the $\chi^{2}$ test for categorical variables and the Student $t$ test or the Wilcoxon rank-sum test for continuous variables. We created Kaplan-Meier plots for patients exposed to combination therapy versus monotherapy, and we used Cox proportional hazards analyses with adjustment for baseline characteristics to explore the association between dual therapy and the risk of the ONTARGET composite renal outcome and of hyperkalemia. Finally, we estimated the median change in glomerular filtration rate among patients given combination therapy who stopped their treatment and calculated the $95 \%$ confidence intervals (CIs) using the bootstrap method with 1000 replications.

This study was approved by the University of Alberta Health Research Ethics Board.

\section{Results}

Of the 282425 residents of Alberta for whom results were available in the central laboratory repository and who were older than 65 years of age, 44301 were new users of an ACE inhibitor, an angiotensin-receptor blocker or a combination of the two; 32312 of them met the criteria for inclusion in our cohort (Figure 1). Although we were able to examine rates of hyperkalemia and stoppage of treatment among all of the patients in the cohort, we were able to analyze the composite renal outcome for only the 24800 patients who had serum creatinine measured before and after they had started treatment.

Of the 32312 patients, most received mono therapy with either an ACE inhibitor (19567 [60.6\%]) or an angiotensin-receptor blocker (9259 [28.7\%]). Of the remaining 3486 patients, 1736 $(5.4 \%)$ were given sequential monotherapy (i.e., an ACE inhibitor or an angiotensin-receptor blocker first, and a subsequent switch to the other drug class without any overlap), and 1750 (5.4\%) were given combination therapy. Of the patients given combination therapy, 1361 were given both medications within 120 days of their first pre- scription, and 393 were initially given monotherapy for at least 120 days before being given combination therapy. The number of patients receiving combination therapy was similar across all years of the study (Appendix 1, available at www .cmaj.ca/cgi/content/full/cmaj.101333/DC1).

Although the age distributions among patients given monotherapy and those given combination therapy were similar, men were significantly less likely than women to be given combination therapy (Table 1).

Compared with patients given monotherapy, those receiving combination therapy were more likely to have hypertension or proteinuria and to have been prescribed other cardiovascular medications (Table 1). However, 1512 (86.4\%) of the patients receiving combination therapy did not have heart failure or proteinuria. (Each patient was counted only once in determining that 1512 patients did not have indications for combination therapy, although some patients on combination therapy had multiple indications, such as heart

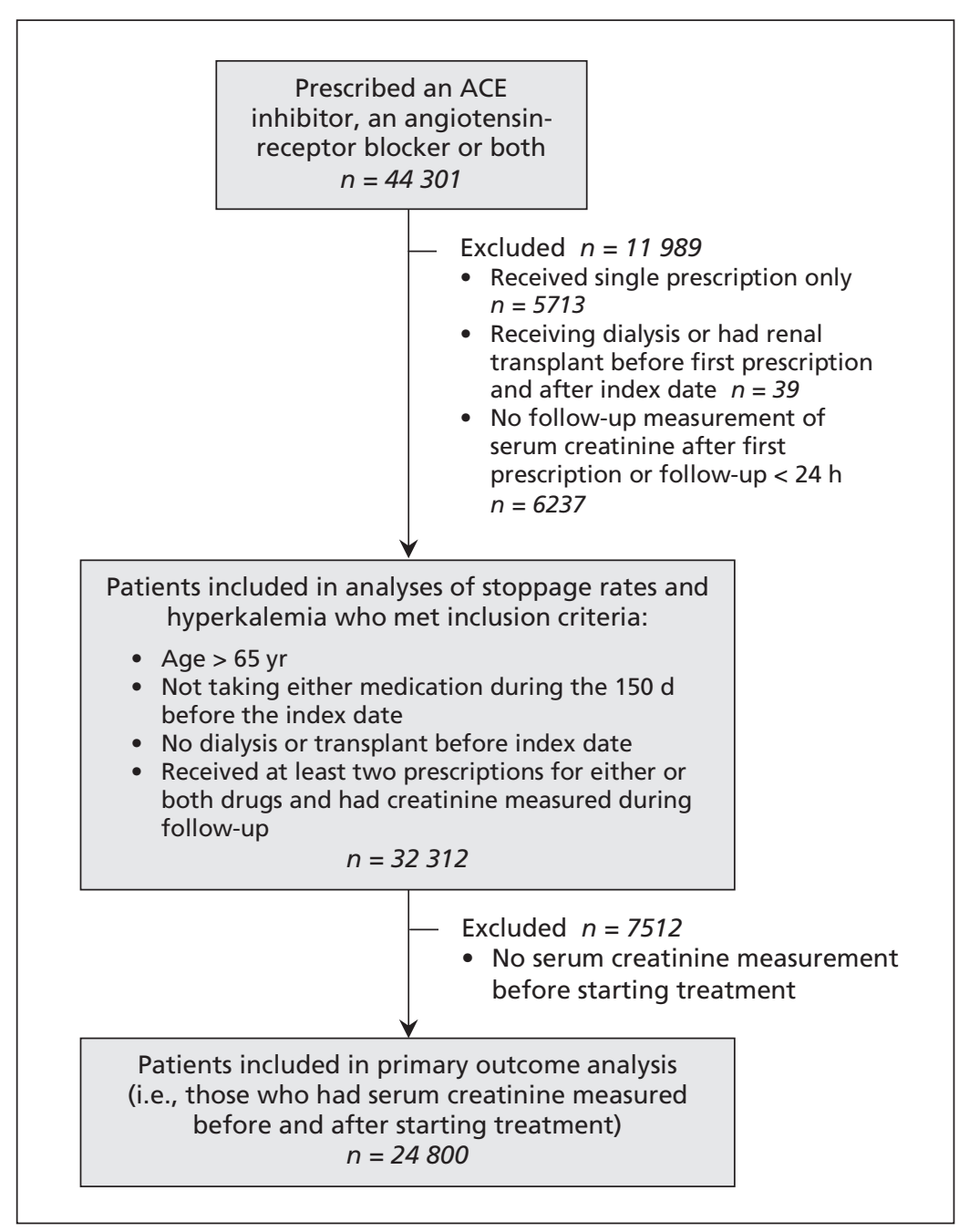

Figure 1: Flow chart showing selection of study cohort. ACE = angiotensinconverting enzyme. 


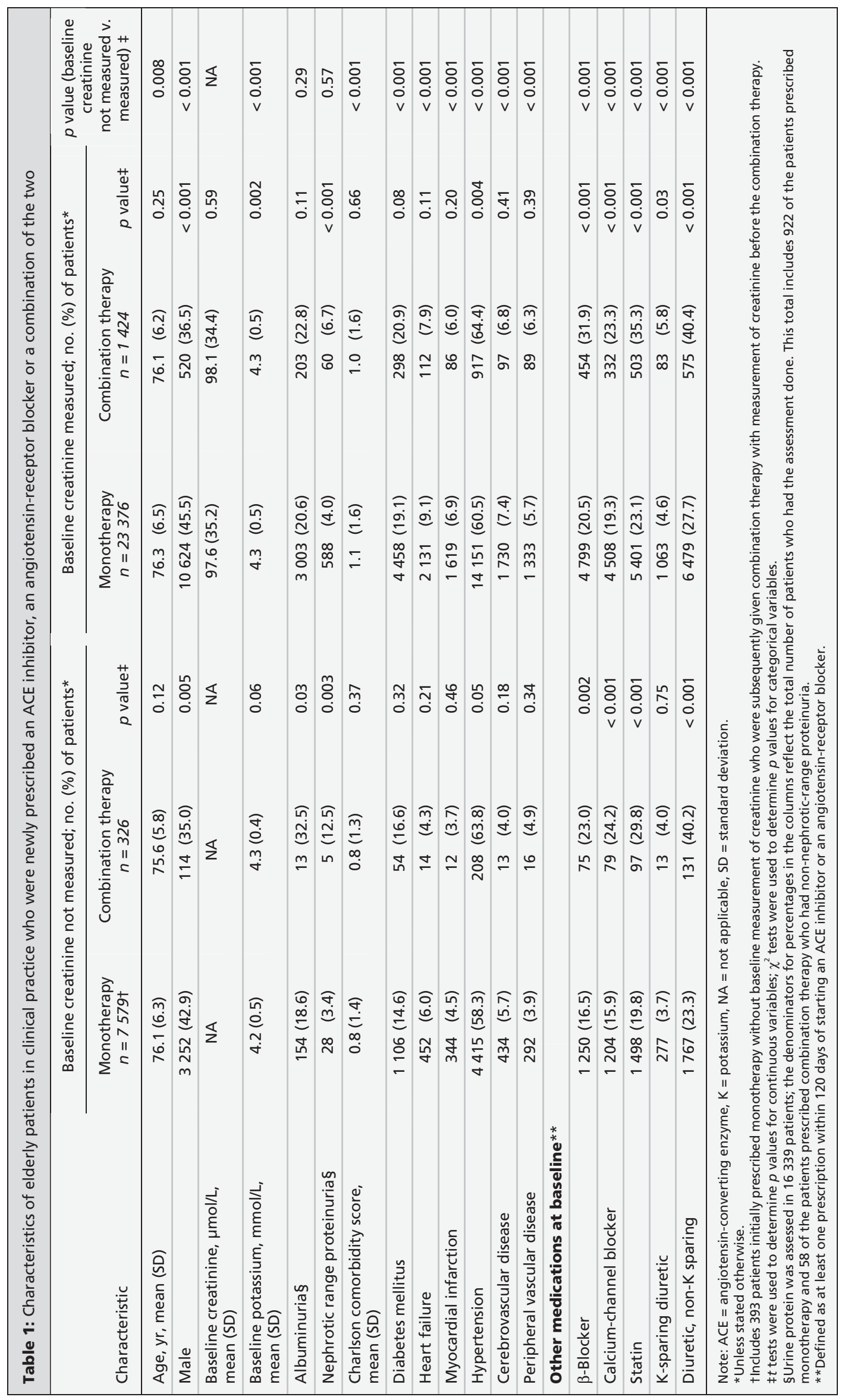


failure and proteinuria.) Serum creatinine and potassium levels were similar between groups (Table 1): the glomerular filtration rate was greater than $60 \mathrm{~mL} / \mathrm{min}$ per $1.73 \mathrm{~m}^{2}$ in 14710 patients $(59.3 \%), 45-60 \mathrm{~mL} / \mathrm{min}$ per $1.73 \mathrm{~m}^{2}$ in 7005 patients (28.2\%), $30-45 \mathrm{~mL} / \mathrm{min}$ per $1.73 \mathrm{~m}^{2}$ in 2534 patients $(10.2 \%$ ) and less than $30 \mathrm{~mL} / \mathrm{min}$ per $1.73 \mathrm{~m}^{2}$ in 551 patients $(2.2 \%)$.

Compared with patients who did not have serum creatinine measured at baseline, those who did were more likely to be male, to be older, to have diabetes, hypertension, heart failure or a higher score on the Charlson comorbidity index, or to be taking diuretics, statins, $\beta$-blockers or calcium-channel blockers at baseline (Table 1). Patients who had a follow-up creatinine measurement taken after they started taking an ACE inhibitor or an angiotensin-receptor blocker were also more likely than those who did not have follow-up creatinine measurement to have albuminuria, to have had a prior myocardial infarction, or to have had a cerebral or peripheral vascular disease (data not shown).

The duration of combination therapy (median 3 [interquartile range 2-4] months) was substantially shorter than the duration of monotherapy (median 13 [interquartile range 8-23] months) (Appendix 2, available at www.cmaj.ca/cgi /content/full/cmaj.101333/DC1). Most of those who stopped combination therapy showed little change in their glomerular filtration rate before they stopped treatment (median change -0.9 [95\% CI -1.6 to -0.2$]$ ) (Appendix 3, available at www.cmaj.ca/cgi/content/full/cmaj.101333/DC1). Most patients (1542 [88.1\%]) who stopped receiving combination therapy did not stop both medications altogether but were instead switched to monotherapy.

Our primary composite outcome was more common (Figure 2) among patients given combination therapy (5.2 [95\% CI 3.4 to 7.9] events per 1000 patients per month) than among patients given monotherapy $(2.4$ [95\% CI 2.2 to 2.7], events per 1000 patients per month), even after multivariable adjustment (Table 2, adjusted hazard ratio (HR) $2.36,95 \%$ CI 1.51 to 3.71 ). Of the 350 patients in whom the primary outcome was seen during follow-up, 120 showed a doubling in serum creatinine, 20 had end-stage renal disease, and 234 died. When more than one primary outcome event occurred (22 patients), only the first event was included in the analyses. The mean changes in glomerular filtration rate $\left(-1.3 \mathrm{~mL} / \mathrm{min}\right.$ per $1.73 \mathrm{~m}^{2}$ v. $-1.6 \mathrm{~mL} / \mathrm{min}$ per $1.73 \mathrm{~m}^{2} ; t$ test, $\left.p=0.52\right)$ and serum potassium $(+0.02 \mathrm{mmol} / \mathrm{L} \mathrm{v} .+0.07$ $\mathrm{mmol} / \mathrm{L} ; t$ test, $p=0.06$ ) were similar between the two therapy groups.

Measurement of baseline creatinine was an independent risk factor for end-stage renal disease or death (HR 2.18, 95\% CI 1.51 to 3.15), which suggested that clinicians were more vigi-
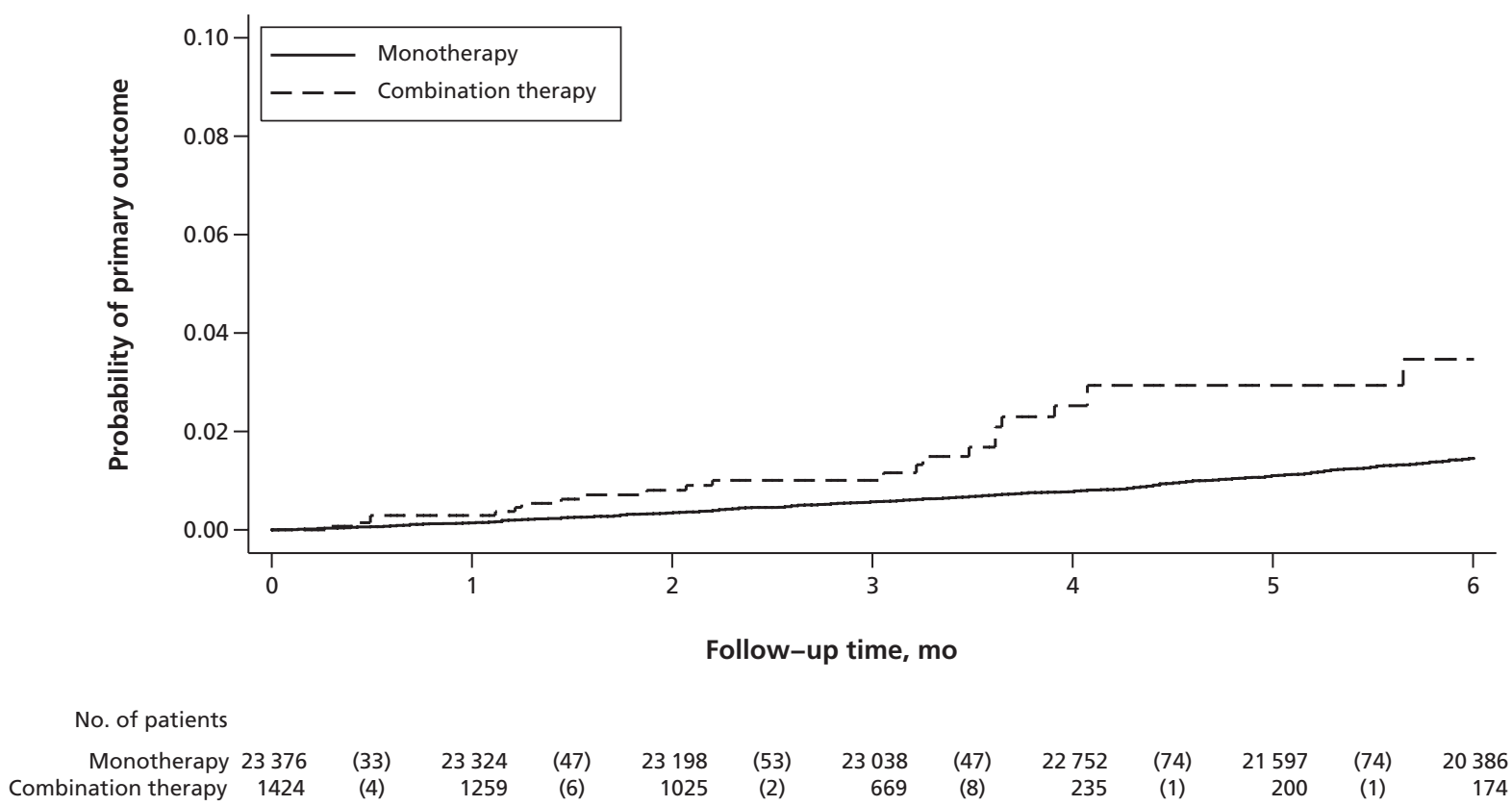

Figure 2: Kaplan-Meier curves for primary outcome (doubling of serum creatinine, development of end-stage renal failure or death from any cause) among the 24800 patients for whom serum creatinine was measured before and after the start of treatment. Numbers in parentheses are the number of patients who had at least one of the three outcome events. Hazard ratio $2.36(95 \%$ confidence interval 1.51 to 3.71 ). 
Table 2: Factors associated with risk of primary outcome* in a Cox proportional hazards model

\begin{tabular}{|c|c|c|}
\hline Covariate & $\begin{array}{c}\text { No. of } \\
\text { patients }\end{array}$ & $\begin{array}{c}\text { Adjusted HR } \\
(95 \% \mathrm{Cl}) \dagger\end{array}$ \\
\hline
\end{tabular}

\section{Therapy group}

Monotherapy

$(95 \% \mathrm{Cl}) \dagger$

Combination therapy

Age at baseline, yr

$66-70$

$71-75$

$76-80$

$81-85$

$\geq 86$

Sex

Male

Female

Glomerular filtration rate at baseline,

$\mathrm{mL} / \mathrm{min}$ per $1.73 \mathrm{~m}^{2}$

\begin{tabular}{lrl|}
$\geq 60$ & 14710 & 1.00 \\
$45-60$ & 7005 & $0.99(0.76-1.29)$ \\
$30-45$ & 2534 & $1.29(0.94-1.77)$ \\
$<30$ & 551 & $3.33(2.25-4.92)$
\end{tabular}

\section{Charlson comorbidity index}

$\begin{array}{lrl}0 & 12601 & 1.00 \\ 1-2 & 8876 & 1.80(1.38-2.34) \\ 3-4 & 2360 & 2.30(1.65-3.21) \\ \geq 5 & 963 & 3.99(2.71-5.88)\end{array}$

\section{Diabetes mellitus at baseline}

\begin{tabular}{lrl} 
No & 20044 & 1.00 \\
Yes & 4756 & $1.41(1.10-1.80)$ \\
\hline Hypertension at baseline & 9732 & 1.00 \\
\hline No & 15068 & $0.70(0.56-0.88)$ \\
Yes & & \\
\hline$\beta$-Blocker at baseline & 19547 & 1.00 \\
\hline No & 5253 & $1.14(0.88-1.48)$ \\
\hline Yes & &
\end{tabular}

Calcium-channel blocker

at baseline

\begin{tabular}{|c|c|c|}
\hline No & 19960 & 1.00 \\
\hline Yes & 4840 & $1.11(0.86-1.43)$ \\
\hline \multicolumn{3}{|c|}{ Statin at baseline } \\
\hline No & 18896 & 1.00 \\
\hline Yes & 5904 & $0.75(0.56-1.00)$ \\
\hline \multicolumn{3}{|c|}{ K-sparing diuretic at baseline } \\
\hline No & 23654 & 1.00 \\
\hline Yes & 1146 & $1.34(0.89-2.01)$ \\
\hline \multicolumn{3}{|c|}{ Other diuretic at baseline } \\
\hline No & 17746 & 1.00 \\
\hline Yes & 7054 & $1.45(1.14-1.83)$ \\
\hline
\end{tabular}

Note: $\mathrm{Cl}=$ confidence interval, $\mathrm{HR}=$ hazard ratio, $\mathrm{K}=$ potassium.

*The primary outcome was defined as doubling of serum creatinine, development of end-

stage renal failure or death from any cause.

tThe multivariable model incorporated all variables in this Table. lant in their baseline testing of patients at risk of having poorer outcomes. We could not analyze the occurrence of our primary outcome among patients for whom baseline creatinine had not been measured, since this outcome included "doubling of serum creatinine." However, analyzing mortality and the presence of end-stage renal disease in all 32312 patients revealed a similar association between the use of combination therapy and increased risk: HR 3.27 (95\% CI 2.01 to 5.30) for end-stage renal disease requiring dialysis or death with combination therapy versus monotherapy, even after adjustment for the covariates outlined in Table 2.

Hyperkalemia was more common among patients who received combination therapy $(2.5$ [95\% CI 1.4 to 4.3] events per 1000 patients per month) than among patients who received monotherapy (0.9 [95\% CI 0.8 to 1.0 ] events per 1000 patients per month) (adjusted HR $2.42,95 \%$ CI 1.36 to 4.32 ). Multivariable analyses confirmed that the factors associated with an increased risk of hyperkalemia were the same as those associated with an increased risk of the composite renal outcome shown in Table 2 , but they also included the use of potassiumsparing diuretics at baseline (HR 1.82, 95\% CI 1.08 to 3.05$)$. Measurement of creatinine at baseline was also an independent risk factor for hyperkalemia (HR 2.18, 95\% CI 1.35 to 3.50), which again suggests that clinicians were more vigilant in their baseline testing of patients at risk of hyperkalemia.

\section{Interpretation}

We found that less than one-seventh of the elderly residents of Alberta who were given combination therapy in clinical practice had either of the conditions for which this therapy has been proven beneficial in randomized trials (i.e., proteinuria or symptomatic left ventricular systolic dysfunction despite treatment with an ACE inhibitor or an angiotensin-receptor blocker alone)., ${ }^{2,3}$ Second, we found that most patients stopped combination therapy within three months, even though most of them showed minimal change in their renal function. Third, we found that the hazard ratios for hyperkalemia and renal dysfunction with combination therapy closely mirror those reported in RCTs (a recent meta-analysis of trials quoted a risk ratio of 2.12 [95\% CI 1.30 to 3.46] for renal dysfunction). ${ }^{8}$ Although the absolute risks appear to be relatively low in our cohort of elderly patients, a $0.52 \%$ monthly risk of adverse renal outcomes is not insubstantial for a drug combination that would need to be taken 
for years to show any nephroprotective or cardioprotective effects. This is particularly relevant when you consider that most of the patients given this combination did not have conditions that have been proven to benefit from concomitant use of an ACE inhibitor and an angiotensin-receptor blocker.

Although data from RCTs suggest that only $12 \%$ of patients stopped taking combination therapy, ${ }^{8}$ our data showed higher rates of stopping treatment, which are consistent with rates reported among patients taking antihypertensive drugs in nontrial settings. ${ }^{16-18}$ However, we have enhanced the existing evidence by showing that most patients who stopped combination therapy showed relatively minor changes in glomerular filtration rate and serum potassium levels before they stopped taking the drug. This evidence suggests that these factors were not why most patients stopped the combination therapy. Although we believe that hypotension may have been the limiting factor in our elderly cohort with multiple comorbidities, this is purely speculation on our part; blood pressure measurements were not part of our data set.

\section{Limitations}

Our study captured all of the laboratory and prescribing data from a defined geographic location with universal access to health care. This allowed us to examine the actual rates of laboratory abnormalities (as opposed to just hospital admissions or laboratory visits) among elderly patients who were new users of ACE inhibitors, angiotensin-receptor blockers or a combination of the two. A new-user design is considered the most suitable design for assessing the risk of medication-related adverse events. ${ }^{19}$

Nonetheless, our data have some limitations. For example, because we used prescription dispensations to define drug use, we may have underestimated both the frequency with which treatment was stopped and the risk of adverse events. ${ }^{20}$ Our follow-up of laboratory results included only the first six months after the initial prescription was filled; however, previous work has shown that if follow-up testing is done, it is usually done within the first month of a new prescription. ${ }^{21}$ Moreover, we did not evaluate whether patients who stopped taking their medication(s) subsequently restarted.

We prespecified our definitions of hyperkalemia and the composite renal outcome; more liberal definitions of hyperkalemia (e.g., potassium level $\geq 5.5 \mathrm{mmol} / \mathrm{L}$ ) or renal dysfunction would have undoubtedly lead to greater effect estimates.

Finally, determination of laboratory-based outcomes depends on the frequency of monitoring.
Therefore it is impossible to directly compare the absolute rates of renal dysfunction or hyperkalemia in our cohort with the rates reported in RCTs.

\section{Conclusion}

It had been speculated that the renal toxicity of combined therapy with an ACE inhibitor and an angiotensin-receptor blocker reported in RCTs may not be seen in clinical practice, where clinicians could individualize the dosing of both drugs and presumably minimize the risk of renal toxicity. ${ }^{5,10}$ However, we found that the use of combination therapy among elderly patients in clinical practice was associated with increased risks of adverse renal outcomes and hyperkalemia compared with monotherapy. Our most striking findings were that combination therapy was commonly prescribed for patients who did not have the trial-proven indications and that it was frequently stopped after only a few months, even when hyperkalemia or renal dysfunction did not occur.

\section{References}

1. Werner C, Baumhäkel M, Teo KK, et al. RAS blockade with $\mathrm{ARB}$ and $\mathrm{ACE}$ inhibitors: current perspective on rationale and patient selection. Clin Res Cardiol 2008;97:418-31.

2. Lee VC, Rhew DC, Dylan M, et al. Meta-analysis: angiotensinreceptor blockers in chronic heart failure and high-risk acute myocardial infarction. Ann Intern Med 2004;141:693-704.

3. Kunz R, Friedrich C, Wolbers M, et al. Meta-analysis: effect of monotherapy and combination therapy with inhibitors of the renin angiotensin system on proteinuria in renal disease. Ann Intern Med 2008; 148:30-48.

4. Pfeffer MA, McMurray JJV, Velazquez EJ, et al.; VALIANT Investigators. Valsartan, captopril, or both in myocardial infarction complicated by heart failure, left ventricular dysfunction, or both. N Engl J Med 2003;349:1893-906.

5. Yusuf S, Teo KK, Pogue J, et al.; for The ONTARGET Investigators. Telmisartan, ramipril, or both in patients at high risk for vascular events. N Engl J Med 2008;358:1547-59.

6. Mann JFE, Schmieder RE, McQueen M; ONTARGET Investigators. Renal outcomes with telmisartan, ramipril, or both, in people at high vascular risk (the ONTARGET Study): a multicentre, randomized, double-blind, controlled trial. Lancet 2008;372:547-53.

7. Lakhdar R, Al-Mallah MH, Lanfear DE. Safety and tolerability of angiotensin-converting enzyme inhibitor versus the combination of angiotensin-converting enzyme inhibitor and angiotensin receptor blocker in patients with left ventricular dysfunction: a systematic review and meta-analysis of randomized controlled trials. J Card Fail 2008;14:181-8.

8. Phillips CO, Kashani A, Ko DK, et al. Adverse effects of combination angiotensin II receptor blockers plus angiotensin-converting enzyme inhibitors for left ventricular dysfunction. Arch Intern Med 2007; 167:1930-6.

9. Ioannidis JP, Lau J. Completeness of safety reporting in randomized trials: an evaluation of 7 medical areas. JAMA 2001; 285:437-43.

10. Messerli FH. Dual renin-angiotensin system blockade in heart failure [letter]. J Am Coll Cardiol 2009;54:279-80.

11. Hemmelgarn BR, Clement F, Manns BJ, et al. Overview of the Alberta Kidney Disease Network. BMC Nephrol 2009;10:30.

12. Quan H, Parsons GA, Ghali WA. Validity of information on comorbidity derived from ICD-9-CM administrative data. Med Care 2002;40:675-85.

13. Halpern MT, Khan ZM, Schmier JK, et al. Recommendations for evaluating compliance and persistence with hypertension therapy using retrospective data. Hypertension 2006;47:1039-48.

14. Fitz-Simon N, Bennett K, Feely J. A review of studies of adherence with antihypertensive drugs using prescription databases. Ther Clin Risk Manag 2005;1:93-106.

15. Quan H, Khan N, Hemmelgarn B, et al. Validation of a case definition to define hypertension using administrative data. Hypertension 2009;54:1423-8. 
16. Burke TA, Sturkenboom MC, Lu S, et al. Discontinuation of antihypertensive drugs among newly diagnosed hypertensive patients in UK general practice. J Hypertens 2006;24:1193-200.

17. Gu Q, Paulose-Ram R, Dillon C, et al. Antihypertensive medication use among US adults with hypertension. Circulation 2006;113:213-21.

18. Friedman O, McAlister FA, Yun L, et al.; CHEP Outcomes Research Taskforce. Antihypertensive drug persistence and compliance among newly treated elderly hypertensives in Ontario. Am J Med 2010;123:173-81.

19. Ray WA. Evaluating medication effects outside of clinical trials: new-user designs. Am J Epidemiol 2003;158:915-20.

20. Vrijens B, Vincze G, Kristanto P, et al. Adherence to prescribed antihypertensive drug treatments: longitudinal study of electronically compiled dosing histories. BMJ 2008;336:1114-7.

21. McAlister FA, Tu K, Majumdar SR, et al. Laboratory testing in newly treated elderly hypertensive patients without comorbidities: a population-based cohort study. Open Med 2007;1:e60-7.

Affiliations: From the Division of General Internal Medicine and Mazankowski Alberta Heart Institute (McAlister), University of Alberta, Edmonton, Alta; the Department of Medicine (Zhang, Manns, Hemmelgarn), University of Calgary, Calgary, Alta.; the Division of Nephrology (Tonelli, Klarenbach),
University of Alberta, Edmonton, Alta.; and the Department of Community Health Sciences (Manns, Hemmelgarn), University of Calgary, Calgary, Alta.

Contributors: Finlay McAlister and Brenda Hemmelgarn designed the study. Marcello Tonelli, Scott Klarenbach, Braden Manns, Brenda Hemmelgarn and Jianguo Zhang obtained the data; Jianguo Zhang ran the analyses under the supervision of Finlay McAlister and Brenda Hemmelgarn. Finlay McAlister wrote the first draft of the paper, and all of the authors contributed to the interpretation of the data and revisions of the manuscript. Finlay McAlister is the guarantor for this study.

Funding: Finlay McAlister, Marcello Tonelli, Scott Klarenbach and Brenda Hemmelgarn are supported by salary awards from the Alberta Heritage Foundation for Medical Research (AHFMR). Marcello Tonelli, Braden Manns and Brenda Hemmelgarn were supported by awards from the Canadian Institutes of Health Research. This work was supported by a grant from the AHFMR Interdisciplinary Team Grants Program (the Interdisciplinary Chronic Disease Collaboration Grant). None of the funders had any role in the present study.

\section{Change of address}

We require 6 to 8 weeks' notice to ensure uninterrupted service. Please send your current mailing label, new address and the effective date of change to:

\section{CMA Member Service Centre}

1870 Alta Vista Dr. Ottawa ON K1G 6R7

tel $888855-2555$ or

$613731-8610 \times 2307$

fax $613236-8864$

cmamsc@cma.ca

\section{Changement d'adresse}

II nous faut de 6 à 8 semaines d'avis afin de vous assurer une livraison ininterrompue. Veuillez faire parvenir votre étiquette d'adresse actuelle, votre nouvelle adresse et la date de la prise d'effet du changement, à l'attention du

\section{Centre des services aux membres de l'AMC}

1870, prom. Alta Vista

Ottawa ON K1G 6R7

tél 888 855-2555 ou

$613731-8610 \times 2307$

fax 613 236-8864

cmamsc@cma.ca

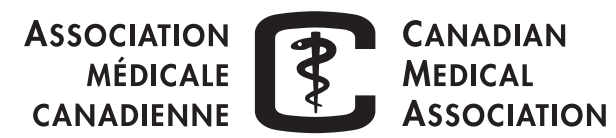

